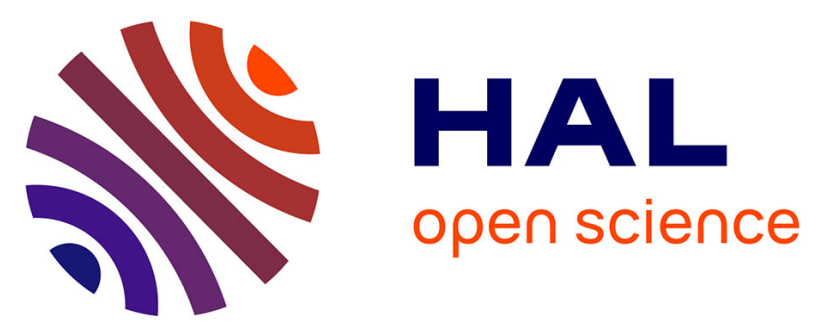

\title{
Decreasing perinatal mortality in the Netherlands, 2000-2006: a record linkage study
}

\author{
Anita C J Ravelli, Miranda Tromp, Marian M van Huis, Eric a P Steegers, \\ Pieter Tamminga, Martine Eskes, Gouke J Bonsel
}

\section{- To cite this version:}

Anita C J Ravelli, Miranda Tromp, Marian M van Huis, Eric a P Steegers, Pieter Tamminga, et al.. Decreasing perinatal mortality in the Netherlands, 2000-2006: a record linkage study. Journal of Epidemiology and Community Health, 2009, 63 (9), pp.761-n/a. 10.1136/jech.2008.080440 . hal00477871

\section{HAL Id: hal-00477871 \\ https://hal.science/hal-00477871}

Submitted on 30 Apr 2010

HAL is a multi-disciplinary open access archive for the deposit and dissemination of scientific research documents, whether they are published or not. The documents may come from teaching and research institutions in France or abroad, or from public or private research centers.
L'archive ouverte pluridisciplinaire HAL, est destinée au dépôt et à la diffusion de documents scientifiques de niveau recherche, publiés ou non, émanant des établissements d'enseignement et de recherche français ou étrangers, des laboratoires publics ou privés. 
Title page

Decreasing perinatal mortality in the Netherlands, 2000-2006:

a record linkage study

Anita CJ Ravelli, PhD; Miranda Tromp, MSc; Marian van Huis; Eric AP

Steegers, MD, PhD; Pieter Tamminga, MD; Martine Eskes, MD, PhD; Gouke

J Bonsel MD, PhD

From the Department of Medical Informatics (Dr Ravelli, Drs Tromp and Dr Eskes);

the Department of Obstetrics \& Gynecology (van Huis); the Department of

Neonatology \& Pediatrics (DrsTamminga), Academic Medical Center, Amsterdam;

the Division of Obstetrics and Prenatal Medicine, University Medical Center,

Rotterdam (Prof. Steegers); the Department of Health Policy and Management,

Erasmus MC, Rotterdam (Prof. Bonsel), the Netherlands.

Correspondence: Dr ACJ Ravelli, Department of Medical Informatics, Academic

Medical Center, PO Box 22700, 1100 DE Amsterdam, The Netherlands. E-mail:

a.c.ravelli@amc.uva.nl, Tel +31205664624, Fax +31206919840.

Word count text $=2439$ words.

Abstract $=231$ words .

Competing Interest: none declared.

"The Corresponding Author has the right to grant on behalf of all authors and does grant on behalf of all authors, an exclusive licence (or non exclusive for government employees) on a worldwide basis to the BMJ Publishing Group Ltd and its Licensees to permit this article (if accepted) to be published in JECH editions and any other BMJPGL products to exploit all subsidiary rights, as set out in our licence (http://jech.bmj.com/ifora/licence.pdf)". 


\section{ABSTRACT}

Background: The European PERISTAT-1 study showed that in 1999 perinatal mortality, especially fetal mortality, was substantially higher in the Netherlands when compared to other European countries. The aim of this study was to analyze the recent trend in Dutch perinatal mortality and the influence of risk factors.

Methods: A nationwide retrospective cohort study of 1,246,440 singleton births in 2000-2006 in the Netherlands. The source data were available from three linked registries: the midwifery registry, the obstetrics registry and the neonatology/pediatrics registry. The outcome measure was perinatal mortality (fetal and early neonatal mortality). The trend was studied with and without risk adjustment. Five clinical distinct groups with different perinatal mortality risks were used to gain further insight.

Results: Perinatal mortality among singletons declined from 10.5 to 9.1 per 1000 total births in the period 2000-2006. This trend remained significant after full adjustment (odds ratio 0.97 [95\% $\mathrm{Cl} 0.96-0.98]$ ) and was present in both fetal and neonatal mortality. The decline was most prominent among births complicated by congenital anomalies, among premature births (32.0-36.6 weeks) and among term births. Home births showed the lowest mortality risk. Conclusions: Dutch perinatal mortality steadily declined which could not be explained by changes in known risk factors including high maternal age and non-western ethnicity. The decline was present in all risk groups except in the 
very premature births. The mortality level still is high compared to European standards.

\section{Keywords}

Perinatal mortality, trend analysis, risk factors, term birth, congenital anomalies.

\section{What this paper add box}

\section{What is already known on this subject?}

- Perinatal mortality, especially fetal mortality, is substantially higher in the Netherlands when compared to other European countries (PERISTAT study).

- The effect of different risk factors, like maternal age and ethnicity, on recent Dutch perinatal mortality is unknown.

\section{What does this study add?}

- Since 2000 there is a steady decline in both fetal and neonatal mortality in the Netherlands which could not be explained by changes in known risk factors.

- Population Attributive Risk for different risk factors of perinatal mortality showed that non-Western ethnicity is important and nulliparity even more.

- Home births showed the lowest mortality risk. 
BODY OF THE TEXT

\section{Introduction}

Perinatal mortality is an indicator of reproductive health and quality of obstetric health care.[1-3] The European PERISTAT-1 study showed that in 1999 perinatal mortality, especially fetal mortality, was substantially higher in the Netherlands when compared to other European countries.[4] Dutch civil registration issued crude perinatal mortality data showing a decline in perinatal mortality since 2000 , however the civil registration has a limited set of risk factors for detailed analysis.[5]

Trends in perinatal mortality can be explained by changes in the prevalence of risk factors or by changes in the impact of risk factors. [6, 7] The effect of risk factors on the outcome can be influenced by health care factors. Perinatal mortality is known to be higher among teenage and older mothers, first and multiple births and births from non-western women.[8, 9] Several changes in risk and health care factors took place in recent years. Maternal age further increased. The obstetric management of term breech presentation changed since the Term Breech Trial.[10] The number of midwives increased and the Neonatal Intensive Care Unit (NICU) capacity was extended.

The objective of this paper is to describe the 7-year crude and risk adjusted trend in Dutch perinatal mortality based on linked detailed nationwide perinatal registry data.

\section{Materials and Methods}


Data sources

The Dutch Perinatal Registry (PRN) contains population based detailed information on pregnancies, deliveries and (re)admissions occurring until 28 days after delivery, collected by caregivers. Source data are available from three independent registries: the midwifery registry (LVR1), the obstetrics registry (LVR2) and the neonatology/pediatrics registry (LNR).The midwifery and obstetrics registries start at booking visit and contain complete perinatal data from 20.0 gestational weeks onwards. The neonatology registry contains only data in case of hospital admissions of newborns. The completeness of the PRN registry is $96 \%$ of all births in the Netherlands.[11] The cohort dataset has been created by a validated probabilistic record linkage algorithm of the three health care registries without a personal identifier.[12, 13] For this study the years 2000-2006 have been combined. To accommodate WHO reporting criteria we included all pregnancies from 22.0 gestational weeks onwards.[14] If gestational age was unknown, births with a birth weight below 500 grams were excluded. The study was limited to singleton pregnancies.

\section{Outcome measurements and determinants}

The primary outcome measurement was perinatal mortality, defined as the number of fetal deaths (stillbirths) and neonatal deaths in the first week of life per 1000 total births. Fetal mortality was defined as the number of fetal deaths per 1000 total births. Early neonatal mortality was defined as neonatal deaths in the first week of life per 1,000 live births and late neonatal mortality are deaths between 7 and 27 days of life per 1000 live births. 
Socio-demographic risk factors were: maternal age, parity (0 first birth, 1 second birth, 2-3 third and fourth birth, 4+ fifth or higher birth), ethnicity and urbanization. Ethnicity was classified by the health care provider and combined in Western (ethnic Dutch and other Western) and Non-Western (ethnic groups of Surinamese Creole, Surinamese Hindustani, Moroccan, Turkish's and other non-western countries). Urbanization was based on the number of household per zip code area: very urban (> 2500 households per square kilometer), urban/rural (between 500 and 2500 households) and very rural $(<500$ households).

Obstetric risk factors were: assisted conception, medical condition woman and male gender. Assisted conception covered all non-spontaneous conceptions. Maternal medical condition is the combination of existent medical disorders (essential hypertension, diabetes, cardiac disease and endocrine disease) and medical complications developed during gestation as gestational diabetes and hypertensive pregnancy complications (pregnancy induced hypertension, pre-eclampsia and HELLP).

Gestational age, birth weight and congenital anomalies are intermediate indicators of perinatal mortality and are highly interrelated. The presence of congenital anomalies was based on the information at or shortly after birth. Based on the gestational age and the presence of congenital anomalies we defined five clinical relevant groups with different perinatal mortality risk. These groups were: very preterm births (22.0-25.6 weeks), births with congenital anomalies ( $\geq 26.0$ weeks), preterm births (26.0-31.6 weeks) without congenital anomalies, preterm births (32.0-36.6 weeks) without congenital anomalies and term births ( $\geq 37.0$ weeks) without congenital 
anomalies. According to Dutch national obstetrics/neonatology guidelines, women with a gestational age below 32.0 weeks should deliver in a tertiary hospital. Within the term group ( $\geq 37.0$ weeks), low risk women can start labor under supervision of an independent midwife (with a choice for homebirth or hospital). High risk women start labor under supervision of an obstetrician in the hospital. Selection on high risk is based on national guidelines for referral.[15]

\section{Statistical analysis}

The incidence of perinatal mortality was analyzed for the years 2000-2006 and a Chi-Square test was used to test the presence of a trend. Logistic regression modeling was used to determine the effect of year of birth in combination with other risk factors on perinatal mortality expressed as odds ratios (OR) with $95 \%$ confidence intervals $(95 \% \mathrm{Cl})$. Interaction between year and risk factor was tested for each factor separately. In addition we calculated the population attributive risk percentage based on the prevalence $(P)$ and relative risk $(\mathrm{RR})\left(\mathrm{PAR} \%=\left(\mathrm{P}^{*}(\mathrm{RR}-1) /\left(\mathrm{P}^{*}(\mathrm{RR}-1)+1\right)\right)^{*} 100\right)$ for each factor. [16] Subsequently, the prevalence and mortality risk for the five risk groups were analyzed. The change in prevalence and mortality risk from 2000 to 2006 was determined for the five risk groups. The SAS software version 9.1 was used (SAS institute Inc, Cary NC). 


\section{Results}

Between 2000 and 2006 the perinatal mortality among singletons declined from 10.5 to 9.1 per 1,000 total births $(14 \%$, Chi-Square $p<0.001)$. This was an average decline of $2.0 \%$ a year (Table 1 ). Both fetal and early neonatal mortality declined: fetal mortality from 7.5 to 6.4 per 1,000 total births (15\%, Chi-Square $p<0.001$ ) and early neonatal mortality from 3.1 to 2.7 per 1,000 live births $(13 \%$, Chi-Square $\mathrm{p}<0.02)$. There was no decline in late neonatal mortality ( 0.5 to 0.5 per 1,000 live births, Chi-Square $p=0.69$ ). The decline in perinatal mortality was also present among multiple pregnancies from 37.1 to 28.9 per 1000 births (data not shown). 
Table 1 Fetal, neonatal early/late and perinatal mortality rates of singletons from 22.0 weeks in the Netherlands in 2000- 2006.

\begin{tabular}{|c|c|c|c|c|c|c|c|c|c|c|}
\hline \multirow{2}{*}{$\begin{array}{l}\text { Singleton } \\
\text { Year }\end{array}$} & \multirow{2}{*}{$\begin{array}{l}\text { Total born children } \\
\text { n }\end{array}$} & \multirow{2}{*}{$\begin{array}{l}\text { Total live born } \\
\mathbf{n}\end{array}$} & \multicolumn{2}{|c|}{$\begin{array}{l}\text { Fetal mortality } \\
22.0 \text { weeks }\end{array}$} & \multicolumn{2}{|c|}{$\begin{array}{c}\text { Early } \\
\text { Neonatal } \\
\text { mortality 0-6 } \\
\text { days }\end{array}$} & \multicolumn{2}{|c|}{$\begin{array}{l}\text { Late neonatal } \\
\text { mortality } 7-27 \\
\quad \text { days }\end{array}$} & \multicolumn{2}{|c|}{$\begin{array}{l}\text { Perinatal mortality } \\
22.0 \text { - } 6 \text { days }\end{array}$} \\
\hline & & & $\mathbf{n}$ & $\%$ & $\mathbf{n}$ & $\%$ & $\mathbf{n}$ & $\%$ & $\mathbf{n}$ & $\%$ \\
\hline 2000 & 183,627 & 182,246 & 1,381 & 7.5 & 556 & 3.1 & 92 & 0.5 & 1,937 & 10.5 \\
\hline 2001 & 182,156 & 180,750 & 1,406 & 7.7 & 539 & 3.0 & 88 & 0.5 & 1,945 & 10.7 \\
\hline 2002 & 181,702 & 180,360 & 1,342 & 7.4 & 537 & 3.0 & 86 & 0.5 & 1,879 & 10.3 \\
\hline 2003 & 183,550 & 182,301 & 1,249 & 6.8 & 551 & 3.0 & 76 & 0.4 & 1,800 & 9.8 \\
\hline 2004 & 175,117 & 173,956 & 1,161 & 6.6 & 441 & 2.6 & 71 & 0.4 & 1,602 & 9.1 \\
\hline 2005 & 170,677 & 169,559 & 1,118 & 6.6 & 500 & 3.0 & 85 & 0.5 & 1,618 & 9.5 \\
\hline 2006 & 169,611 & 168,525 & 1,086 & 6.4 & 449 & 2.7 & 85 & 0.5 & 1,535 & 9.1 \\
\hline $\begin{array}{l}2000- \\
2006\end{array}$ & $1,246,440$ & $1,237,697$ & 8,743 & 7.1 & 3,573 & 2.9 & 583 & 0.5 & 12,316 & 9.9 \\
\hline
\end{tabular}


Year effect and risk factors for perinatal mortality

The effect of the calendar year of birth was OR 0.97 (95\% Cl 0.96-0.98) both crude and adjusted for risk factors (see table 2). None of the risk factors showed a significant interaction with year. The risk factors maternal age and parity were U-shaped related to perinatal mortality with age category 25-34 years and parity 1 as optimal categories. The PAR of nulliparity was $14.8 \%$. The mean age of nulliparous women was 28.8 years. Sixteen percent of the pregnant women were from non-western origin, the ethnic effect on perinatal mortality was OR $1.4(95 \% \mathrm{Cl} 1.3-1.5)$ and the PAR was 6.6\%. Assisted conception and the presence of a maternal medical condition increased the risk on perinatal mortality (OR of 1.7 and 1.6 respectively). 
Table 2

Unadjusted and adjusted odds ratio's and PAR \% of risk factors for perinatal mortality (22.0 weeks-6 days) of singletons in 2000-2006.

\begin{tabular}{|c|c|c|c|c|c|c|c|c|c|c|c|c|}
\hline Risk Factor & $\begin{array}{l}\text { Prevalence } \\
\text { risk factor }\end{array}$ & $\begin{array}{l}\text { Absolute } \\
\text { mortality } \\
\text { mean/ } \\
\text { year }\end{array}$ & \multicolumn{3}{|c|}{$\begin{array}{c}\text { Unadjusted } \\
\text { Perinatal mortality }\end{array}$} & \multicolumn{3}{|c|}{$\begin{array}{c}\text { Adjusted }^{* 1} \\
\text { Perinatal mortality }\end{array}$} & \multicolumn{3}{|c|}{$\begin{array}{l}\text { Adjusted }^{\text {*2 }} \\
\text { Perinatal mortality }\end{array}$} & \multirow[t]{2}{*}{$\begin{array}{c}\text { PAR\% } \\
\text { Perinatal } \\
\text { mortality }\end{array}$} \\
\hline Year effect & $\begin{array}{r}\% \\
100.0 \%\end{array}$ & $\begin{array}{r}\mathbf{n} \\
1,759\end{array}$ & $\begin{array}{r}\text { Odds } \\
\text { ratio } \\
0.97\end{array}$ & $\begin{array}{r}95 \% \mathrm{Cl} \\
0.96\end{array}$ & 0.98 & $\begin{array}{r}\text { Odds } \\
\text { ratio }\end{array}$ & $95 \% \mathrm{Cl}$ & & $\begin{array}{r}\text { Odds } \\
\text { ratio } \\
0.97\end{array}$ & $\begin{array}{r}95 \% \mathrm{Cl} \\
0.96\end{array}$ & 0.98 & \\
\hline \multicolumn{13}{|l|}{ Maternal age (years) } \\
\hline age $<20$ & $1.8 \%$ & 50 & 1.80 & 1.62 & 2.00 & 1.58 & 1.41 & 1.76 & 1.57 & 1.41 & 1.75 & 1.4 \\
\hline age $20-24$ & $10.2 \%$ & 214 & 1.32 & 1.25 & 1.40 & 1.22 & 1.15 & 1.29 & 1.22 & 1.15 & 1.29 & 3.1 \\
\hline age $25-34$ & $68.6 \%$ & 1,096 & 1.00 & & & 1.00 & & & 1.00 & & & \\
\hline age 35-39 & $17.0 \%$ & 332 & 1.22 & 1.17 & 1.28 & 1.20 & 1.14 & 1.26 & 1.21 & 1.15 & 1.27 & 3.6 \\
\hline age $>=40$ & $2.5 \%$ & 68 & 1.75 & 1.59 & 1.92 & 1.51 & 1.38 & 1.67 & 1.53 & 1.39 & 1.68 & 1.8 \\
\hline \multicolumn{13}{|l|}{ Parity } \\
\hline par 0 Nulliparous & $46.3 \%$ & 895 & 1.38 & 1.32 & 1.44 & 1.31 & 1.25 & 1.37 & 1.31 & 1.25 & 1.36 & 14.8 \\
\hline parity 1 & $35.8 \%$ & 504 & 1.00 & & & 1.00 & & & 1.00 & & & \\
\hline parity $2-3$ & $16.0 \%$ & 294 & 1.31 & 1.24 & 1.38 & 1.24 & 1.18 & 1.31 & 1.24 & 1.18 & 1.31 & 4.6 \\
\hline parity 4+ & $2.5 \%$ & 66 & 2.42 & 2.20 & 2.67 & 1.98 & 1.79 & 2.19 & 1.97 & 1.78 & 2.18 & 2.7 \\
\hline Non-western ethnicity & $16.2 \%$ & 382 & 1.45 & 1.38 & 1.51 & 1.39 & 1.33 & 1.46 & 1.40 & 1.33 & 1.47 & 6.6 \\
\hline \multicolumn{13}{|l|}{ Level of urbanization } \\
\hline very urban & $19.5 \%$ & 374 & 1.12 & 1.07 & 1.17 & 0.99 & 0.94 & 1.03 & 0.99 & 0.94 & 1.03 & 2.3 \\
\hline medium urban/rural & $62.6 \%$ & 1,074 & 1.00 & & & 1.00 & & & 1.00 & & & \\
\hline very rural & $17.9 \%$ & 311 & 1.01 & 0.97 & 1.06 & 1.05 & 1.00 & 1.10 & 1.05 & 1.00 & 1.10 & 0.2 \\
\hline
\end{tabular}




\begin{tabular}{lrrrrrrrrrrrrrr} 
Assisted conception & $1.7 \%$ & 53 & 1.79 & 1.62 & 1.99 & 1.71 & 1.54 & 1.90 & 1.71 & 1.54 & 1.90 & & & \\
$\begin{array}{l}\text { Medical condition } \\
\text { woman }\end{array}$ & $9.5 \%$ & 255 & 1.63 & 1.55 & 1.71 & 1.59 & 1.51 & 1.67 & 1.59 & 1.52 & 1.68 & & 5.7 \\
Male gender child & $51.4 \%$ & 935 & 1.07 & 1.04 & 1.11 & 1.07 & 1.04 & 1.11 & 1.07 & 1.04 & 1.11 & 3.6 \\
\hline
\end{tabular}

${ }^{* 1}$ Adjusted for maternal age, parity, ethnicity, urbanization, assisted conception, medical condition and male gender.

${ }^{* 2}$ Adjusted for maternal age, parity, ethnicity, urbanization, assisted conception, medical condition, male gender and year.

PAR= population-attributable risk

n.a. $=$ not applicable 
Risk groups

Table 3 shows the prevalence and perinatal mortality risks for the five risk groups. Almost one third (29\%) of all perinatal deaths occurred among the very preterm births and $26 \%$ of the perinatal deaths occurred among births from 37.0 weeks gestation onwards. Overall there were relatively 270 less mortality cases observed in 2006 than would be expected based on prevalence and mortality risks in 2000 . The perinatal mortality risk declined and was most prominent among births with congenital anomalies (45\% decline), among preterm births with 32.0 - 36.6 weeks gestation ( $30 \%$ decline) and among the term births (25\% decline). 
Table 3

Prevalence and mortality risk of risk groups and the relative difference in prevalence and mortality risk of singletons for 2006 compared to 2000

\begin{tabular}{|c|c|c|c|c|c|c|c|c|c|c|c|}
\hline \multirow[t]{3}{*}{ Risk groups } & \multicolumn{2}{|l|}{ Prevalence } & \multicolumn{2}{|c|}{$\begin{array}{l}\text { Perinatal } \\
\text { mortality }\end{array}$} & \multirow[t]{2}{*}{ Contribution } & \multicolumn{3}{|c|}{ Prevalence } & \multicolumn{3}{|c|}{ Mortality risk } \\
\hline & & & & & & 2000 & 2006 & Difference & 2000 & 2006 & Difference \\
\hline & $\mathbf{n}$ & $\%$ & $\mathbf{n}$ & $\%$ & $\%$ & $\%$ & $\%$ & $\%$ & $\%$ & $\%$ & $\%$ \\
\hline Very premature 22.0-25.6 weeks & 3,865 & 0.31 & 3,614 & 935 & 29 & 0.28 & 0.36 & 27 & 931 & 912 & $-2 \%$ \\
\hline$\geq 26.0$ weeks \& congenital anomalies & 29,228 & 2.34 & 1,937 & 66 & 16 & 2.25 & 2.78 & 24 & 84 & 46 & $-45 \%$ \\
\hline $\begin{array}{l}26.0-31.6 \text { weeks } \\
\text { no congenital anomalies }\end{array}$ & 8,775 & 0.70 & 1,953 & 223 & 16 & 0.72 & 0.69 & -4 & 232 & 195 & $-16 \%$ \\
\hline $\begin{array}{l}32.0-36.6 \text { weeks } \\
\text { no congenital anomalies }\end{array}$ & 58,864 & 4.72 & 1,562 & 27 & 13 & 5.01 & 4.61 & -8 & 27 & 19 & $-30 \%$ \\
\hline $\begin{array}{l}\geq 37.0 \text { weeks } \\
\text { no congenital anomalies }\end{array}$ & $1,145,708$ & 91.9 & 3,250 & 2.8 & 26 & 91.74 & 91.56 & 0 & 3.3 & 2.4 & $-25 \%$ \\
\hline Total & $1,246,440$ & 100 & 12,316 & 9.9 & 100 & 100.00 & 100.00 & & 10.5 & 9.1 & \\
\hline
\end{tabular}


Health Care factors

The percentage of elective caesarean sections in term pregnancies complicated by breech presentation nearly doubled from $30 \%$ in 2000 to $58 \%$ in 2006. The perinatal mortality risk in term breech presentation decreased from $5.6 \%$ o to $3.0 \%$. $52 \%$ of the term women were selected as low risk at the start of the delivery and $48 \%$ as high risk. The perinatal mortality risk of the low risk group was 1.3 and of the high risk group 4.5 per 1000 births. Perinatal mortality declined in both low and high risk term groups; from $1.7 \%$ o to $1.0 \%$ 。 for the low risk group and from $5.0 \%$ o to $3.8 \%$ ofor the high risk group. Within the low risk group the perinatal mortality risk declined from 0.5 to 0.4 for home deliveries, from 2.8 to 0.9 for hospital deliveries under supervision of an independent midwife and from 3.2 to 2.4 for transferrals to high risk during delivery.

\section{Discussion}

Perinatal mortality declined from 10.5 per 1000 total births in 2000 to 9.1 per 1000 total singleton births in 2006. The decline remained significant after adjustment for important significant risk factors like teenage pregnancy, maternal age $\geq 40$ years, nulliparity, parity $\geq 4$, non-western ethnicity, urbanization, assisted conception and maternal medical condition. The decline was most prominent among births with congenital anomalies, preterm births (32.0-36.6) and among term pregnancies but was absent in the very premature births. 


\section{Strengths and weaknesses}

The large dataset with national coverage and many available variables allowed for a detailed analysis of both risk and health care factors. National databases usually lack information on this level. The combined information from midwifes, gynecologists and neonatologists could be used for analyses due to the application of a probabilistic linking algorithm. Validation of this algorithm showed less than $1 \%$ errors.[12, 13] Discrepancies on important risk factors among linked records were lower than $2 \%$. In general, in case of discrepancies, the value of the health care provider involved at the moment of occurrence was used. If congenital anomalies or mortality had been registered by one of the involved caregivers, it was assumed to have occurred. When the registry data were compared with civil registration data, the quality of the outcome measurements was high; fetal deaths were more often registered in the PRN registration, especially the very preterm fetal deaths. The risk factors age, parity, ethnicity and zip code showed less than $1 \%$ missing values. The prevalence of medical condition of the women before and during pregnancy could be underestimated as this variable is not obliged in the registry, but there is no indication that changes occurred in registering this information during the studied period. The analyses of perinatal mortality in five risk groups with different patterns of care allowed for analyses of changes in perinatal mortality in relation to daily (clinical) practice.

Some important risk factors for perinatal mortality such as level of education, smoking during pregnancy, body mass index of the woman and food and folic acid intake were not captured in the current registry. Severe smoking during 
pregnancy is an item in the registry, but this information was not used because of the low prevalence $(0.5 \%)$ due to underreporting. In general, about $10-15 \%$ of the pregnant women smoke during pregnancy in the Netherlands.[17] When severe smoking (OR 1.5, 95\% Cl 1.2-1.9) was included in the adjusted model no effect on the trend odds ratio was visible. It is unknown if the prevalence and perinatal mortality risk of the unmeasured risk factors changed during the study period and contributed to the decline.

The high level of Dutch perinatal mortality in 1999 compared to other European countries was explained by several risk factors: the restrictive policy to resuscitate and to perform intensive treatment of very preterm infants, the absence of a prenatal screening program for congenital anomalies and substandard care including home-birth. Other risk factors mentioned were multiple births, advanced maternal age, high parity, non-western ethnicity, smoking, maternal obesity, increased birth weight and more complete registration through professional instead of civil registrations.[5, 18] The present study showed that the changes in prevalence of women with a high maternal age and of women from non-western origin did not play an important role in the trend in perinatal mortality. We showed also that the prevalence of home deliveries in term infants $27 \%$ is paired with a very low perinatal mortality risk (0.4 per 1000 births).

Our study confirmed the large share of very preterm infants in perinatal mortality; $29 \%$ of the total perinatal mortality. The Dutch restricted resuscitation policy in the spontaneous very preterm births did not change during the period 2000-2006.[19, 20] The prevalence of very preterm infants, 
however, increased, especially from 2005 to 2006. The proportion of congenital anomalies within the very premature birth group increased from 15 to $26 \%$. Termination of pregnancy after detection of structural anomalies in late second- trimester screening influences the prevalence of very preterm births and the mortality rate. $[19,21,22]$ Termination of pregnancy is no explicit item in the registry but a high percentage of induction was found among births from $22.0-25.6$ weeks gestation (48\% in 2000 and $57 \%$ in 2006) indicating late terminations of pregnancy. This is most likely the result of the inception of the national prenatal ultrasound screening program for structural abnormalities (around 20 weeks of gestation) in the period 2004/2005 which was consolidated in 2006.

The decline of the perinatal mortality risk in term breech presentations illustrates the rapid and successful implementation of the Hannah trial results. ${ }^{[10]}$ However due to low prevalence of breech presentation the contribution to the overall decline in perinatal mortality was minimal. The perinatal mortality decline in both low and high risk women at term is remarkable and might indicate the influence of care factors like more and better trained perinatal health professionals and better use of facilities including NICU beds.

The decline in perinatal mortality after 2000 has been described in other countries as well. 1[23-25] Detailed analyses separately for fetal and neonatal mortality can give further insight into the role of risk factors.[26] The elevated perinatal mortality risk among ethnic groups, also after adjustment, is a matter of concern. A national audit of perinatal mortality cases is essential to define substandard care factors in relation to the cause of death. 
In conclusion the Dutch perinatal mortality declined from 2000 to 2006, which could not be explained by changes in known risk factors. The decline was present in all risk groups except in the very premature births.

\section{Acknowledgements}

The authors would like to thank all Dutch midwives, obstetricians, neonatologists and other perinatal healthcare providers for the registration of perinatal information. We also like to thank the Foundation of the Netherlands Perinatal Registry (www.perinatreg.nl) for the permission of using the registry data. In the PRN registry the LVR1, LVR2 and LNR registries from the Royal Dutch Midwifery Organization (KNOV), the Dutch Association for Obstetrics and Gynecology (NVOG) and the Pediatric Association of the Netherlands (NVK) are combined to one perinatal database.

\section{Funding}

none 


\section{Reference}

\section{Reference List}

1 Zeitlin J, Wildman K, Breart G, Alexander S, Barros H, Blondel B, et al. PERISTAT: indicators for monitoring and evaluating perinatal health in Europe. Eur J Public Health 2003;13(3 Suppl):29-37.

2 Richardus JH, Graafmans WC, Verloove-Vanhorick SP, Mackenbach JP. Differences in perinatal mortality and suboptimal care between 10 European regions: results of an international audit. BJOG 2003;110(2):97-105.

3 Newnham JP. Improving outcomes in pregnancy. BMJ 2007;334(7598):807-8.

4 Buitendijk S, Zeitlin J, Cuttini M, Langhoff-Roos J, Bottu J. Indicators of fetal and infant health outcomes. Eur J Obstet Gynecol Reprod Biol 2003;111 Suppl 1:S66-S77.

5 Garssen J, Meulen Avd. Perinatal mortality in the Netherlands Backgrounds on worsening international ranking. Demographic Research 2004;11(13):357-94.

6 Yuan H, Platt RW, Morin L, Joseph KS, Kramer MS. Fetal deaths in the United States, 1997 vs 1991. Am J Obstet Gynecol 2005;193(2):489-95.

7 Glinianaia SV, Rankin J, Bell R, Pearce MS, Parker L. Temporal changes in the distribution of population risk factors attenuate the reduction in perinatal mortality. J Clin Epidemiol 2005;58(12):1299-307.

8 Ravelli ACJ, Eskes M, Tromp M, Huis van A, Steegers EA, Tamminga P, et al. [Perinatal mortality in the Netherlands 2000-2006; risk factors and risk selection]. Ned Tijdschr Geneeskd 2008;152(50):2728-33.

9 Smith GC, Fretts RC. Stillbirth. Lancet 2007;370(9600):1715-25.

10 Rietberg CC, Elferink-Stinkens PM, Visser GH. The effect of the Term Breech Trial on medical intervention behaviour and neonatal outcome in The Netherlands: an analysis of 35,453 term breech infants. BJOG 2005;112(2):205-9.

11 Stichting Perinatale Registratie Nederland. Perinatal Care in the Netherlands 2006. 2008. Utrecht.

12 Meray N, Reitsma JB, Ravelli AC, Bonsel GJ. Probabilistic record linkage is a valid and transparent tool to combine databases without a patient identification number. J Clin Epidemiol 2007;60(9):883-91. 
13 Tromp M, Ravelli AC, Meray N, Reitsma JB, Bonsel GJ. An efficient validation method of probabilistic record linkage including readmissions and twins. Methods Inf Med 2008;47(4):356-63.

14 World Health Organization. Neonatal and Perinatal Mortality. Country, Regional and global estimates. Geneva: 2006.

15 Bleker OP, Hulst van der LAM, Eskes M, Bonsel GJ. Place of birth: evidence for best practice. In: Bonnar J, Dunlop W, editors. Recent advantage in Obstetrics and Gynaecology 23.London: Royal Society of Medicine Press; 2005. p. 77100.

16 Miettinen OS. Proportion of disease caused or prevented by a given exposure, trait or intervention. Am J Epidemiol 1974;99(5):325-32.

17 Troe EJ, Raat H, Jaddoe VW, Hofman A, Steegers EA, Verhulst FC, et al. Smoking during pregnancy in ethnic populations: the Generation R study. Nicotine Tob Res 2008;10(8):1373-84.

18 Treffers PE. [Forty years of discussion about perinatal mortality in the Netherlands]. Ned Tijdschr Geneeskd 2004;148(38):1853-5.

19 De Leeuw R, Cuttini M, Nadai M, Berbik I, Hansen G, Kucinskas A, et al. Treatment choices for extremely preterm infants: an international perspective. J Pediatr 2000;137(5):608-16.

20 Zeitlin J, Gwanfogbe CD, Delmas D, Pilkington H, Jarreau PH, Chabernaud JL, et al. Risk factors for not delivering in a level III unit before 32 weeks of gestation: results from a population-based study in Paris and surrounding districts in 2003. Paediatr Perinat Epidemiol 2008;22(2):126-35.

21 van der Pal-de Bruin KM, Graafmans W, Biermans MC, Richardus JH, Zijlstra AG, Reefhuis J, et al. The influence of prenatal screening and termination of pregnancy on perinatal mortality rates. Prenat Diagn 2002;22(11):966-72.

22 Papiernik E, Zeitlin J, Delmas D, Draper ES, Gadzinowski J, Kunzel W, et al. Termination of pregnancy among very preterm births and its impact on very preterm mortality: results from ten European population-based cohorts in the MOSAIC study. BJOG 2008;115(3):361-8.

23 Fanaroff AA, Stoll BJ, Wright LL, Carlo WA, Ehrenkranz RA, Stark AR, et al. Trends in neonatal morbidity and mortality for very low birthweight infants. Am J Obstet Gynecol 2007;196(2):147-8.

24 Scioscia M, Vimercati A, Maiorano A, Depalo R, Selvaggi L. A critical analysis on Italian perinatal mortality in a 50-year span. Eur J Obstet Gynecol Reprod Biol 2007;130(1):60-5.

25 Anonymous. Defining perinatal mortality. Lancet 2007;369(9572):1492.

26 Kramer MS, Liu S, Luo Z, Yuan H, Platt RW, Joseph KS. Analysis of perinatal mortality and its components: time for a change? Am J Epidemiol 2002;156(6):493-7. 